\title{
Increased Granulocyte Colony-stimulating Factor Responsiveness but Normal Resting Granulopoiesis in Mice Carrying a Targeted Granulocyte Colony-stimulating Factor Receptor Mutation Derived from a Patient with Severe Congenital Neutropenia
}

\author{
Morgan L. McLemore, Jennifer Poursine-Laurent, and Daniel C. Link \\ Division of Bone Marrow Transplantation and Stem Cell Biology, Department of Medicine, and Department of Pathology, Washington \\ University Medical School, St. Louis, Missouri 63110
}

\begin{abstract}
The role of mutations of the granulocyte colony-stimulating factor receptor (G-CSFR) in the pathogenesis of severe congenital neutropenia (SCN) and the subsequent development of acute myeloid leukemia (AML) is controversial. Mice carrying a targeted mutation of their G-CSFR that reproduces the mutation found in a patient with SCN and AML have been generated. The mutant G-CSFR allele is expressed in a myeloid-specific fashion at levels comparable to the wildtype allele. Mice heterozygous or homozygous for this mutation have normal levels of circulating neutrophils and no evidence for a block in myeloid maturation, indicating that resting granulopoiesis is normal. However, in response to G-CSF treatment, these mice demonstrate a significantly greater fold increase in the level of circulating neutrophils. This effect appears to be due to increased neutrophil production as the absolute number of G-CSF-responsive progenitors in the bone marrow and their proliferation in response to G-CSF is increased. Furthermore, the in vitro survival and G-CSF-dependent suppression of apoptosis of mutant neutrophils are normal. Despite this evidence for a hyperproliferative response to G-CSF, no cases of AML have been detected to date. These data demonstrate that the G-CSFR mutation found in patients with SCN is not sufficient to induce an SCN phenotype or AML in mice. (J. Clin. Invest. 1998. 102:483-492.) Key words: neutropenia/congenital $\bullet$ point mutations - receptors, granulocytic colonystimulating factor $\cdot$ leukemia $\cdot$ mice, transgenic
\end{abstract}

This study was presented in preliminary form at the annual meeting of the American Society of Hematology, San Diego, December 1997. Blood. 1997. 90:1918a (Abstr.)

Address correspondence to Daniel C. Link, Washington University Medical School, Division of Bone Marrow Transplantation and Stem Cell Biology, Box 8007, 660 South Euclid Avenue, St. Louis, MO 63110-1093; Phone: 314-362-8771; FAX: 314-362-9333; E-mail: link@IM.wustl.edu

Received for publication 26 February 1998 and accepted in revised form 28 May 1998.

J. Clin. Invest.

(c) The American Society for Clinical Investigation, Inc. 0021-9738/98/08/0483/10 \$2.00

Volume 102, Number 3, August 1998, 483-492

http://www.jci.org

\section{Introduction}

Severe congenital neutropenia (SCN), ${ }^{1}$ or Kostmann's syndrome, is a rare, usually autosomal recessive disorder characterized by severe neutropenia present from birth $(1,2)$. Absolute neutrophil counts are usually $<200$ cells per cubic millimeter, with the remainder of the blood counts relatively normal. The bone marrow invariably shows an arrest in myeloid maturation with an accumulation of promyelocytes or myelocytes. Because of their neutropenia, patients with SCN suffer from chronic life threatening infections. Treatment with granulocyte colony-stimulating factor (G-CSF) leads to an increase in neutrophil counts to $>1,000$ cells per cubic millimeter in $90 \%$ of patients resulting in significant improvements in survival and quality of life $(3,4)$.

The molecular defect responsible for SCN is not known. Because G-CSF is the major hematopoietic growth factor regulating the production of neutrophils and as the defect in hematopoiesis in SCN appears to be limited to granulopoiesis, studies investigating the role of G-CSF and its receptor (GCSFR) in the pathogenesis of $\mathrm{SCN}$ have been performed. G-CSF levels are normal or increased in patients with SCN (57). Furthermore, the G-CSFR has been found to be present at normal or increased levels on myeloid cells (7-9). However, in $\sim 25 \%$ of patients with $\mathrm{SCN}$, mutations of one allele of the G-CSFR have been detected (10). These mutations invariably are single nucleotide substitutions that introduce premature stop codons leading to a truncation of the distal cytoplasmic portion of the G-CSFR (10-13). Interestingly, this region has been implicated in the generation of maturation signals by the G-CSFR (12,14-16). These observations have led to the hypothesis that the loss of maturation signals by the mutant G-CSFR may contribute to the block in myeloid maturation seen in patients with SCN.

SCN patients are at increased risk of developing acute myelogenous leukemia (AML) or myelodysplasia (MDS). In a recent series, $10 \%$ of patients with SCN followed for five or more years developed AML or MDS (2). Interestingly, pa-

1. Abbreviations used in this paper: AML, acute myeloid leukemia; CFU-G, colony-forming cells granulocyte; G-CSF, granulocyte colony-stimulating factor; G-CSFR, granulocyte colony-stimulating factor receptor; HCP, hematopoietic cell phosphatase; MDS, myelodysplasia; RT-PCR, reverse transcriptase-polymerase chain reaction; $\mathrm{SCN}$, severe congenital neutropenia. 
tients with G-CSFR mutations appear to be at the greatest risk; in the most recent update, 8 of 16 patients with SCN and G-CSFR mutations have developed AML or MDS (10). Conversely, to date, no patients with $\mathrm{SCN}$ without a mutation of their G-CSFR are known to have developed AML or MDS. This striking association has lead to speculation that G-CSFR mutations may contribute to leukemogenesis in these patients.

Collectively, these studies have suggested that G-CSFR mutations may play a role in the pathogenesis of SCN and/or the development of AML/MDS in these patients. To directly test this hypothesis, we generated mice carrying a targeted "knock-in" mutation of their G-CSFR that reproduces the mutation found in a patient with SCN and AML. The effect of this mutation on granulopoiesis, response to G-CSF, and the development of AML or MDS was examined.

\section{Methods}

Construction of the targeting vector. The molecular cloning and mapping of the murine G-CSFR gene has been described previously (17). A PCR-based method was used to generate a $\mathrm{C}$ to $\mathrm{T}$ mutation within exon 17 at nucleotide 2403 (corresponding to the murine G-CSFR cDNA sequence), as described (18). A 3-kb BamHI-HindIII genomic fragment containing exons 15-17 was subcloned into pUC-9. This plasmid (p15-17) was used as the template in PCR reactions with the following oligonucleotide primer pairs: Exon 16 forward primer $\left(5^{\prime}\right.$ CCCACAGTAGCCTGAGCTCC-3') and exon 17 reverse mutagenesis primer (5'-AGAGGAATTCTAGGACTGGTTGGA-3'); exon 17 forward mutagenesis primer (5'-CCAGTCCTAGAATTCCTCTCGCAC- $\left.3^{\prime}\right)$ and exon 17 reverse primer (5'-CCCCAAAGTTCTAGAAACCC- $3^{\prime}$ ). The primary PCR products were purified by gel electrophoresis, annealed in a 1:1 molar ratio, and amplified with the exon 16 forward and exon 17 reverse primers listed above. The resulting product was digested with Sac- 1 and Xba-1 and subcloned into p15-17 that had been digested with Sac-1 and Xba-1. The 3-kb genomic fragment from p15-17 (containing the mutation) along with a 2.8-kb HindIII-BamHI genomic fragment containing the $3^{\prime}$-flanking region of the murine G-CSFR gene were subcloned 5' and $3^{\prime}$, respectively, to a $1.8-\mathrm{kb}$ PGK-neo ${ }^{\mathrm{r}}$ cassette to generate the targeting vector (see Fig. $1 A$ ).

Production of targeted G-CSFR mutant mice. RW4 ES cells (a gift from T.J. Ley, Washington University, St. Louis, MO) were transfected with the Nsi-1-linearized targeting vector, and G418-resistant clones were isolated essentially as described (19). Clones that had undergone homologous recombination were identified by Southern analysis of EcoR1-digested genomic DNA using a 0.4-kb EcoR1Xho1 genomic fragment (see Fig. $1 A$ ) as an external probe. 2 out of 122 G418 resistant clones were identified in this fashion, and the fidelity of the targeted mutation was confirmed by sequence analysis. C57BL/6 blastocysts were microinjected with ES cells from each of these clones and implanted into pseudopregnant Swiss Webster foster females, as described previously (19). Chimeric males with a high percentage of agouti coat color were mated with C57BL/6 females and their offspring examined for germline transmission of the targeted G-CSFR mutation using the Southern analysis procedure described above. Heterozygous mice derived from one of the targeted ES clones were intercrossed to produce homozygous mutant mice. All mice were housed in a specific-pathogen free environment and examined daily by veterinary staff for signs of illness.

Analysis of $m R N A$ expression. Total RNA was prepared from bone marrow mononuclear cells using a guanidinium thiocyanate mini-prep as described (20). Approximately $1 \mu \mathrm{g}$ of RNA was treated with DNase for 15 min and was then reverse transcribed using random primers and AMV-reverse transcriptase (Promega, Madison, WI). The cDNA was amplified using a murine G-CSFR exon 16 forward primer ( $5^{\prime}$-TTGCCCACCATCATGACAGA-3 ${ }^{\prime}$ ) and an exon
17 reverse primer $\left(5^{\prime}\right.$-CCCCAAAGTTCTAGAAACCC- $\left.3^{\prime}\right)$ for 30 cycles at $98^{\circ} \mathrm{C}$ for $45 \mathrm{~s}, 60^{\circ} \mathrm{C}$ for $45 \mathrm{~s}$, and $72^{\circ} \mathrm{C}$ for $1 \mathrm{~min}$. The PCR products were purified using a PCR quick spin column (Qiagen, Chatsworth, CA), digested with EcoR1, and resolved on a 5\% polyacrylamide gel.

Peripheral blood and bone marrow analysis. Blood was obtained by retro-orbital venous plexus sampling in polypropylene tubes containing EDTA. Complete blood counts were determined using a Baker 9000 automated cell counter (Biochem ImmunoSystems, Plano, TX). Bone marrow was harvested by flushing both femoral bones with $\alpha$-minimum essential medium ( $\alpha$-MEM) containing $10 \%$ fetal bovine serum. Manual leukocyte differentials were performed on Wright-stained blood smears or cytospin preparations of bone marrow mononuclear cells.

Flow cytometry. Red blood cells in peripheral blood and bone marrow mononuclear cell preparations were lysed in Tris-buffered ammonium chloride ( $\mathrm{pH}$ 7.2) buffer and incubated with the indicated antibody at $4^{\circ} \mathrm{C}$ for $1 \mathrm{~h}$ in PBS containing $0.1 \%$ sodium azide and $0.2 \%$ bovine serum albumin. The following directly conjugated antibodies were used: Phycoerythrin-conjugated rat anti-mouse CD11b (M1/70, IgG2b; PharMingen, San Diego, CA); FITC-conjugated rat anti-mouse Gr-1(RB6-8C5, IgG2b; PharMingen), and FITC-conjugated rat anti-mouse CD11b (M1/70, IgG2b; PharMingen). To assess surface G-CSFR expression, peripheral blood mononuclear cells were incubated at $4^{\circ} \mathrm{C}$ for $1 \mathrm{~h}$ with biotinylated G-CSF (generated as described (17); 5 ng per $10^{6}$ cells) in the presence or absence of a 100 fold molar excess of nonlabeled G-CSF, followed by incubation with RPE-Cy5-conjugated streptavidin (Dako, Carpinteria, CA). All cells were analyzed using a FACScan ${ }^{\mathrm{TM}}$ flow cytometer and CellQuest version 1.2.2 software (Becton Dickinson, Mansfield, MA).

Hematopoietic progenitor cell assays. Bone marrow mononuclear cells were enumerated with a hemacytometer. A total of 4.0 $8.0 \times 10^{4}$ bone marrow mononuclear cells were plated in $2.5 \mathrm{~mL}$ of methylcellulose media (MethoCult 3230; Stem Cell Technologies, Vancouver, British Columbia, Canada) supplemented with G-CSF at 1,10 , or $100 \mathrm{ng} / \mathrm{mL}$ (Amgen, Thousand Oaks, CA) or with $2.5 \mathrm{~mL}$ of methylcellulose media supplemented with erythropoietin and pokeweed mitogen-stimulated murine spleen cell-conditioned medium (MethoCult 3430; Stem Cell Technologies), and placed in a humidified chamber with $5 \% \mathrm{CO}_{2}$ for $10 \mathrm{~d}$. Colonies containing at least 50 cells were scored on days 7 and 10 . In some experiments, individual colonies were harvested and pooled, the average colony cell number determined using a hemacytometer, and leukocyte differentials performed on Wright-stained cytospin preparations.

G-CSF administration to mice. Recombinant human G-CSF (Amgen) was administered by daily subcutaneous injection at a dose of 10 $\mu \mathrm{g} / \mathrm{kg}$ per day for $7 \mathrm{~d}$. Peripheral blood was obtained before the first G-CSF dose and $4 \mathrm{~h}$ after the injection on day 5 or 7 . Peripheral blood leukocyte counts were analyzed as described above. Mice receiving chronic G-CSF stimulation were injected with a subcutaneous dose of $250 \mu \mathrm{g} / \mathrm{kg}$ twice a week. G-CSF was diluted in PBS with $1 \%$ low endotoxin bovine serum albumin (Sigma Chemical Co., St. Louis, MO).

Apoptosis assay. Neutrophils were purified from the bone marrow of mice using a discontinuous percol gradient exactly as described (21). Neutrophil purity (as assessed by leukocyte differentials) was at least $70 \%$ for both wild-type and mutant preparations. Cells were suspended in $\alpha$-MEM with $10 \%$ fetal bovine serum, 1 $\mathrm{mM} \mathrm{L}$-glutamine, and $10 \mu \mathrm{g} / \mathrm{mL}$ ciprofloxacin, and cultured at $37^{\circ} \mathrm{C}$ and $5 \% \mathrm{CO}_{2}$ for $48 \mathrm{~h}$ in the presence or absence of $100 \mathrm{ng} / \mathrm{mL}$ of G-CSF. Absolute cell numbers were determined using a hemacytometer. To assay for apoptosis, cells were washed once in binding buffer (20 mM Hepes, $132 \mathrm{mM} \mathrm{NaCl}, 1.2 \mathrm{mM}$ potassium phosphate, $5.5 \mathrm{mM}$ glucose, and $0.5 \%$ bovine serum albumin [pH 7.4]), incubated with biotin-conjugated Annexin V (NeXins Research B.V., Roermond, The Netherlands) for $30 \mathrm{~min}$ at $4^{\circ} \mathrm{C}$, and stained with phycoerythrinconjugated streptavidin (GIBCO BRL, Gaithersburg, MD) and actinomycin D, 7-amino (7-AAD; Calbiochem, La Jolla, CA). Analyses were performed on a FACScan ${ }^{\mathrm{TM}}$ flow cytometer. 
$18 \mathrm{~kb}$

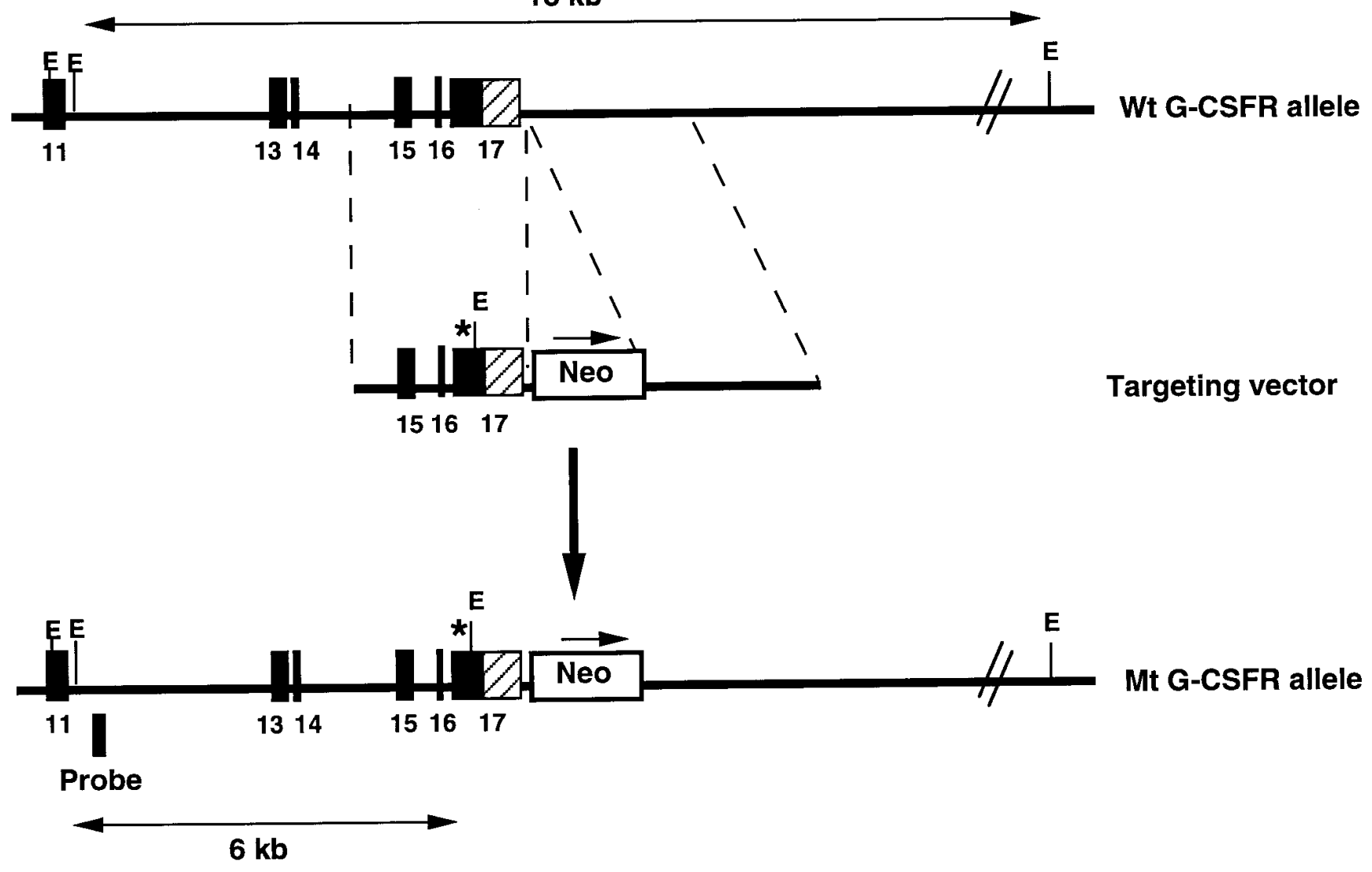

B

\section{$\sum_{\sum}^{+} \quad \sum_{j}^{+\infty} \sum_{j}^{+} \sum_{j}^{+} \sum_{j}^{+}$}

$23.1-$

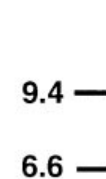

1 $\begin{array}{lll}2 & 3 & 4\end{array}$
Wild-type allele

Mutant allele
Figure 1. Generation of the targeted G-CSFR mutation. (A) Targeting strategy. The genomic organization of the $3^{\prime}$ region of the murine G-CSFR gene is shown. Coding exons are shown as black boxes and the $3^{\prime}$ untranslated region as a hatched box. The targeting vector is shown in the middle panel. The * indicates the $\mathrm{C} \rightarrow \mathrm{T}$ mutation at nucleotide 2403. An EcoR1 site $(E)$ was placed just $3^{\prime}$ to this mutation to facilitate genotyping. Neo represents the neomycin phosphotransferase gene driven by the phosphoglycerate kinase I promoter. Note that the Neo cassette is present in the $3^{\prime}$ untranslated region of the recombined (ML) allele (bottom). (B) Representative Southern blot analysis of EcoR1-digested genomic tail DNA isolated from the progeny of a heterozygous intercross. The location of the probe used for genotyping is shown in $A$. An 18- or 6-kb band is detected from the wild-type allele or mutant allele, respectively. 


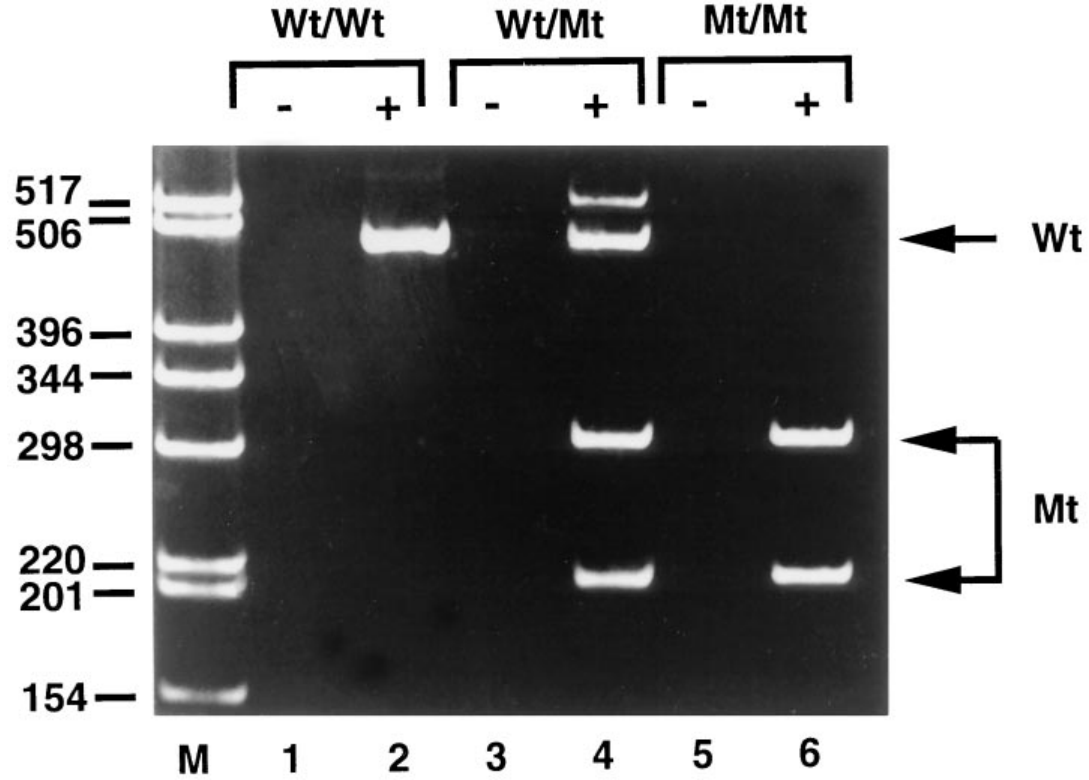

Figure 2. Expression of the mutant allele. $(A)$ RTPCR using primers that flank the mutated region was performed on RNA isolated from bone marrow mononuclear cells of mice of each genotype. Shown is an ethidium bromide-stained polyacrylamide gel of RT-PCR products after treatment with EcoR1. EcoR1 cleaves the mutant $(M t)$ amplicon yielding fragments of 300 and $209 \mathrm{bp}$ but does not cleave the 509 bp wild-type (Wt) amplicon. Lanes 1,3 , and 5 are controls without reverse transcriptase. The faint band at $517 \mathrm{bp}$ in lane 4 was not consistently seen and is of unclear significance. (B) Two-color flow cytometric analysis of peripheral blood mononuclear cells. Peripheral blood mononuclear cells were incubated with Mac-1 ( $x$-axis) and biotinylated G-CSF (y-axis) in the presence (control) or absence of a 100-fold molar excess of nonlabeled G-CSF. The difference between the control and other samples represent specific G-CSF binding. A distinct Mac-1 positive $\mathrm{G}-\mathrm{CSF}$-binding population was noted in cells isolated from mice of each genotype.
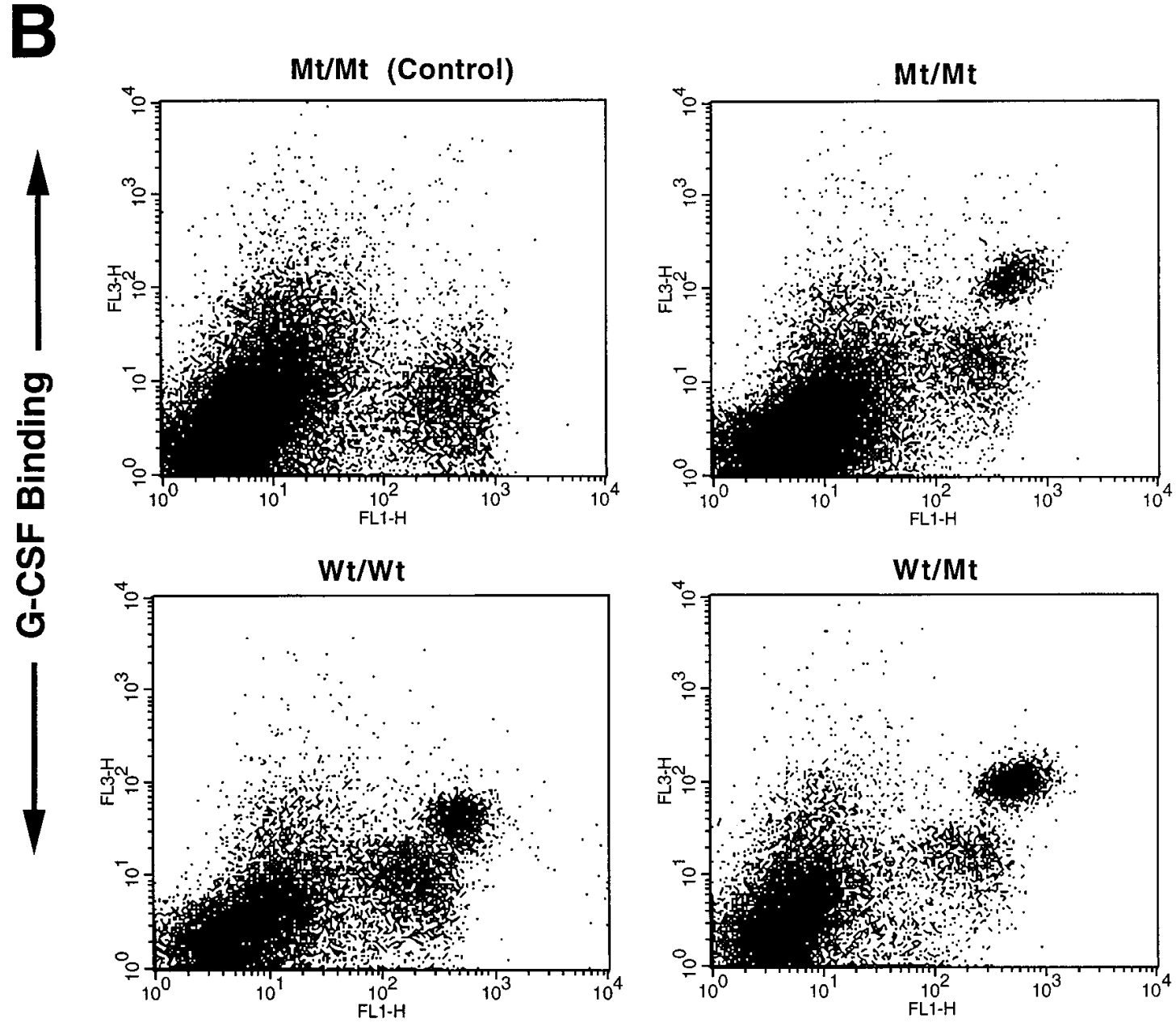

Mac-1 
Statistical analysis. Data are presented as mean \pm SEM. Statistical significance was assessed by Student's $t$ test.

\section{Results}

Generation of transgenic mice with a targeted mutation of their $G$-CSFR gene. A point mutation $(\mathrm{C} \rightarrow \mathrm{T}$ at nucleotide 2403 , based on the murine G-CSFR cDNA) was introduced into exon 17 of the G-CSFR gene using homologous recombination in ES cells (Fig. $1 A$ ). This mutation generates a premature stop codon that leads to truncation of the carboxy-terminal 96 amino acids and reproduces the mutation found in a patient with SCN (12). Two independent targeted clones were identified by Southern blot analysis, and the fidelity of these clones was confirmed by sequence analysis of PCR-amplified DNA from this region. Mice carrying the targeted mutation were generated from one of these clones as described in the Methods section. Progeny from heterozygous intercrosses were genotyped by Southern blot analysis (Fig. $1 B$ ). The expected numbers of heterozygous (Wt/Mt) and homozygous (Mt/ Mt) mutant G-CSFR mice were obtained. These mice have normal growth, development, and fertility, and they are grossly indistinguishable from wild-type (Wt/Wt) littermates.

The mutant G-CSFR is expressed in a myeloid-specific manner. To analyze expression of the mutant allele, reverse transcriptase-polymerase chain reaction (RT-PCR) was performed on RNA isolated from bone marrow mononuclear cells (Fig. $2 \mathrm{~A}$ ). Using primers that flank the targeted region of exons 15 and 17, an amplicon of 509 bp was obtained from both wild-type and mutant RNA. After incubation with EcoR1, only the mutant amplicon is cleaved, allowing for its identification. As expected, only mutant G-CSFR mRNA was detected in mice homozygous for the targeted G-CSFR mutation (Fig. $2 A$, lane 6 ). With RNA isolated from heterozygous mice, similar amounts of wild-type and mutant products were detected (Fig. $2 A$, lane 4 ). These data indicate that the presence of the neomycin phosphotransferase gene in the $3^{\prime}$ untranslated region of the mutant G-CSFR gene does not significantly effect mRNA expression from the mutant allele.

To determine whether the mutant G-CSFR protein was ex- pressed on the surface of hematopoietic cells and capable of binding G-CSF, a flow cytometric method was used to detect specific binding of biotinylated G-CSF. In this assay, peripheral blood mononuclear cells were incubated with biotinylated-G-CSF and antisera to Mac-1 (an antigen expressed on granulocytes, monocytes, and natural killer cells, but not on most lymphocytes). A distinct Mac-1 positive population of cells that specifically bound G-CSF was detected in the peripheral blood of mice of each genotype (Fig. $2 \mathrm{~B}$ ); the slight increase in G-CSF binding seen with $\mathrm{Wt} / \mathrm{Mt}$ or $\mathrm{Mt} / \mathrm{Mt}$ cells was a consistent finding. Forward and side scatter characteristics of this population were consistent with that of neutrophils (data not shown). Importantly, no specific G-CSF binding was detected in the Mac-1 negative (lymphocyte) population. These data indicate that the mutant G-CSFR is expressed in a myeloid-specific fashion.

Mice expressing the mutant G-CSFR have normal resting granulopoiesis. Two cardinal features of SCN are neutropenia and a partial arrest of myeloid maturation $(1,2)$. Examination of peripheral blood at $5,15,25$, and $35 \mathrm{wk}$ of age revealed no significant differences in the white cell, red cell, or platelet count among the three genotypes (Table I). Furthermore, no significant difference in the percentage or absolute number of neutrophils in the peripheral blood was observed. The neutrophils present in $\mathrm{Mt} / \mathrm{Mt}$ mice appeared morphologically normal and expressed normal amounts of Gr-1 and Mac-1 (data not shown). The number and morphology of peripheral blood eosinophils and lymphocytes in these mice also were similar (data not shown).

We next examined hematopoiesis in the bone marrow. Similar numbers of total nucleated cells were recovered from the bone marrow of mice of each genotype (Table II). The percentage and morphology of myeloid precursors was similar. Importantly, no accumulation of promyelocytes or myelocytes was noted, indicating that no block in myeloid maturation exists. Collectively, these data demonstrate that resting granulopoiesis is normal in mice expressing the mutant G-CSFR.

$G$-CSFR mutant mice demonstrate an accentuated response to G-CSF in vivo. Previous studies using immortalized cell lines have suggested that the truncated G-CSFR provides an

Table I. Peripheral Blood Counts

\begin{tabular}{|c|c|c|c|c|c|c|c|}
\hline Genotype & $\begin{array}{l}\text { Age } \\
(\mathrm{wk})\end{array}$ & $n$ & $\begin{array}{c}\text { WBC } \\
\left(\times 10^{-9} / \text { liter }\right)\end{array}$ & $\underset{\left(\times 10^{-12} / \text { liter }\right)}{\mathrm{RBC}}$ & $\begin{array}{l}\text { Platelets } \\
\left(\times 10^{-9} / \text { liter }\right)\end{array}$ & $\begin{array}{l}\text { Neutrophils } \\
(\%)\end{array}$ & $\begin{array}{l}\text { Neutrophils } \\
\left(\times 10^{-9} / \text { liter }\right)\end{array}$ \\
\hline $\mathrm{Wt} / \mathrm{Wt}$ & 5 & 10 & $9.74 \pm 1.06$ & $8.92 \pm 0.26$ & $1025 \pm 33$ & $10.8 \pm 1.7$ & $1074 \pm 270$ \\
\hline $\mathrm{Wt} / \mathrm{Mt}$ & 5 & 10 & $8.56 \pm 1.43$ & $8.83 \pm 0.24$ & $1042 \pm 58$ & $13.2 \pm 3.9$ & $792 \pm 130$ \\
\hline $\mathrm{Mt} / \mathrm{Mt}$ & 5 & 10 & $10.00 \pm 1.04$ & $9.01 \pm 0.19$ & $980 \pm 36$ & $9.1 \pm 1.2$ & $876 \pm 121$ \\
\hline $\mathrm{Wt} / \mathrm{Wt}$ & 15 & 5 & $7.60 \pm 0.60$ & $9.78 \pm 0.69$ & $1005 \pm 95$ & $13.7 \pm 1.3$ & $1054 \pm 157$ \\
\hline $\mathrm{Wt} / \mathrm{Mt}$ & 15 & 5 & $10.90 \pm 2.20$ & $9.60 \pm 0.49$ & $952 \pm 77$ & $9.8 \pm 1.3$ & $1058 \pm 247$ \\
\hline $\mathrm{Mt} / \mathrm{Mt}$ & 15 & 5 & $11.10 \pm 0.70$ & $10.00 \pm 0.38$ & $983 \pm 66$ & $10.2 \pm 1.3$ & $1149 \pm 182$ \\
\hline $\mathrm{Wt} / \mathrm{Wt}$ & 25 & 5 & $10.56 \pm 2.42$ & $10.14 \pm 0.05$ & $993 \pm 114$ & $7.8 \pm 1.5$ & $813 \pm 198$ \\
\hline $\mathrm{Wt} / \mathrm{Mt}$ & 25 & 5 & $13.55 \pm 3.22$ & $10.06 \pm 0.50$ & $986 \pm 64$ & $6.4 \pm 0.9$ & $884 \pm 300$ \\
\hline $\mathrm{Mt} / \mathrm{Mt}$ & 25 & 5 & $9.60 \pm 2.22$ & $10.05 \pm 0.05$ & $1051 \pm 96$ & $8.7 \pm 2.1$ & $836 \pm 319$ \\
\hline $\mathrm{Wt} / \mathrm{Wt}$ & $35-40$ & 4 & $9.48 \pm 1.86$ & $10.55 \pm 0.63$ & $1001 \pm 194$ & $13.6 \pm 1.9$ & $1200 \pm 154$ \\
\hline $\mathrm{Wt} / \mathrm{Mt}$ & $35-40$ & 5 & $10.10 \pm 1.66$ & $10.41 \pm 0.19$ & $1091 \pm 55$ & $11.4 \pm 0.8$ & $1135 \pm 190$ \\
\hline $\mathrm{Mt} / \mathrm{Mt}$ & $35-40$ & 4 & $11.65 \pm 1.19$ & $10.69 \pm 0.19$ & $1181 \pm 39$ & $8.1 \pm 1.8$ & $975 \pm 255$ \\
\hline
\end{tabular}

Manual 300-count leukocyte differentials were performed on blood smears for sex-matched mice. Data represent the mean \pm SEM. 
Table II. Bone Marrow Analysis

\begin{tabular}{lrrr}
\hline \multicolumn{1}{c}{ Nucleated cell type } & $\begin{array}{c}\mathrm{Wt} / \mathrm{Wt} \\
(\% \pm \mathrm{SEM})\end{array}$ & $\begin{array}{c}\mathrm{Wt} / \mathrm{Mt} \\
(\% \pm \mathrm{SEM})\end{array}$ & $\begin{array}{c}\mathrm{Mt} / \mathrm{Mt} \\
(\% \pm \mathrm{SEM})\end{array}$ \\
\hline Total nucleated cells per femur $\left(\times 10^{-6}\right)$ & $19.4 \pm 5.0$ & $19.3 \pm 2.7$ & $18.1 \pm 2.9$ \\
Band and segmented neutrophil & $28.2 \pm 2.7$ & $24.4 \pm 1.6$ & $33.7 \pm 1.4$ \\
Metamyelocyte neutrophil & $13.6 \pm 0.9$ & $13 \pm 2.2$ & $14.5 \pm 0.9$ \\
Myelocyte neutrophil & $6.6 \pm 1.1$ & $5.8 \pm 0.6$ & $7.6 \pm 1.0$ \\
Promyelocytes & $2.4 \pm 0.4$ & $2.5 \pm 0.4$ & $2.2 \pm 0.3$ \\
Myeloblasts & $0.1 \pm 0.0$ & $0.2 \pm 0.1$ & $0.0 \pm 0.0$ \\
Eosinophil lineage & $2.4 \pm 0.4$ & $2.7 \pm 0.3$ & $3.3 \pm 0.6$ \\
Lymphoid lineage & $18.1 \pm 1.3$ & $18.6 \pm 2.1$ & $13.6 \pm 0.9$ \\
Erythroid lineage & $28.5 \pm 2.8$ & $32.6 \pm 2.1$ & $25.1 \pm 1.2$ \\
Myeloid/erythroid ratio & $2.9 \pm 0.3$ & $2.5 \pm 0.2$ & $3.5 \pm 0.4$ \\
& & & \\
& & &
\end{tabular}

Cell counts and 500-count manual leukocyte differentials were performed on mononuclear cells recovered from the femurs of 5-7 mice of each genotype. Wt/Wt, Wt/Mt, and Mt/Mt refer to wild-type, heterozygous, and homozgous mutant mice, respectively. Data represent the mean \pm SEM.

enhanced proliferative signal in response to G-CSF $(12,14)$. To assess the response to G-CSF in vivo, five mice of each genotype were injected with human G-CSF $(10 \mu \mathrm{g} / \mathrm{kg} / \mathrm{day})$ and the change in the level of circulating neutrophils measured (Fig. 3). After $7 \mathrm{~d}$ of treatment, Wt/Mt and Mt/Mt mice had a significantly greater fold increase from baseline in neutrophil counts compared to $\mathrm{Wt} / \mathrm{Wt}$ mice (mean fold increase in neutrophil counts \pm SEM: $\mathrm{Wt} / \mathrm{Wt}=4.22 \pm 0.83 ; \mathrm{Wt} / \mathrm{Mt}=9.56 \pm 1.90 ; \mathrm{Mt} /$ $\mathrm{Mt}=30.67 \pm 7.42$ ). Because the response to G-CSF varies significantly between the two strains of mice used to generate the mutant mice in this study (i.e., C57BL/6 and $129 \mathrm{SvJ}$ ), the response of syngeneic (F1 generation) mice to G-CSF was measured (22). Compared with $\mathrm{Wt} / \mathrm{Wt}$ mice, syngeneic Wt/Mt mice had a significantly greater increment in their neutrophil counts after $7 \mathrm{~d}$ of G-CSF treatment (data not shown). These data indicate that the accentuated response to G-CSF is due to the G-CSFR mutation and not mouse strain differences.

$G$-CSF-dependent suppression of apoptosis in $\mathrm{Mt} / \mathrm{Mt}$ neutrophils is normal. The accentuated response to G-CSF could be secondary to enhanced neutrophil production or prolonged neutrophil survival. To examine the latter possibility, we determined the susceptibility of neutrophils to apoptosis in serumcontaining media in the presence or absence of $100 \mathrm{ng} / \mathrm{mL}$ of G-CSF (Fig. 4). Apoptosis was assessed by Annexin V binding to surface-expressed phosphatidylserine, a sensitive and early marker of apoptosis (23-25). The absolute number of viable nonapoptotic cells was determined by multiply the total cell number by the percentage of cells that were viable (7-AADnegative) and nonapoptotic (Annexin V-negative). As expected, the majority of $\mathrm{Wt} / \mathrm{Wt}$ and $\mathrm{Mt} / \mathrm{Mt}$ neutrophils were nonapoptotic at the initiation of the culture. After $24 \mathrm{~h}$ in media without added G-CSF, a substantial decrease in the absolute number of nonapoptotic cells was observed in cultures of both $\mathrm{Wt} / \mathrm{Wt}$ and $\mathrm{Mt} / \mathrm{Mt}$ neutrophils (percentage of viable nonapoptotic cells present in culture relative to baseline [mean \pm SEM]: $\mathrm{Wt} / \mathrm{Wt}=37 \pm 6 \%, \mathrm{Mt} / \mathrm{Mt}=41 \pm 8 \%)$. In cultures supplemented with G-CSF, apoptosis was suppressed to a similar degree (percentage of viable nonapoptotic cells present in cul- ture relative to baseline $[$ mean $\pm \mathrm{SEM}]: \mathrm{Wt} / \mathrm{Wt}=67 \pm 13 \%$, $\mathrm{Mt} / \mathrm{Mt}=72 \pm 06 \%)$. Likewise, the number of nonapoptotic cells present after $48 \mathrm{~h}$ ( $\pm \mathrm{G}-\mathrm{CSF})$ was similar for cultures of $\mathrm{Wt} / \mathrm{Wt}$ and $\mathrm{Mt} / \mathrm{Mt}$ neutrophils (data not shown). These data indicate that in vitro survival and G-CSF-dependent suppression of apoptosis are normal in $\mathrm{Mt} / \mathrm{Mt}$ neutrophils.

$G$-CSFR mutant mice have increased numbers of G-CSFresponsive progenitors in their bone marrow. To explore possible mechanisms for the increased response to G-CSF in vivo, the response of hematopoietic cells to G-CSF in vitro was examined. In methylcellulose cultures stimulated with pokeweed mitogen-stimulated spleen-conditioned media (a "cocktail" of cytokines that stimulates primarily myeloid progenitors), a similar number of colonies were detected, suggesting that the total number of myeloid progenitors in the bone marrow of these mice was similar (Fig. $5 A$ ). In contrast, an increased number of G-CSF-responsive progenitor cells were detected in cultures of $\mathrm{Wt} / \mathrm{Mt}$ or $\mathrm{Mt} / \mathrm{Mt}$ cells compared with $\mathrm{Wt} / \mathrm{Wt}$ cells (Fig. $5 \mathrm{~B}$ ). Interestingly, no difference in the dose response of these progenitors to G-CSF was observed. Colony-forming cells granulocyte (CFU-G) progenitors have a limited proliferative capacity and colonies derived from these cells typically begin to degenerate after 7-10 d of culture. Examination of cultures on day 10 revealed that, compared to $\mathrm{Wt} / \mathrm{Wt}$ colonies, colonies derived from $\mathrm{Wt} / \mathrm{Mt}$ and $\mathrm{Mt} / \mathrm{Mt}$ progenitors were, on average, larger and showed fewer signs of degeneration. In

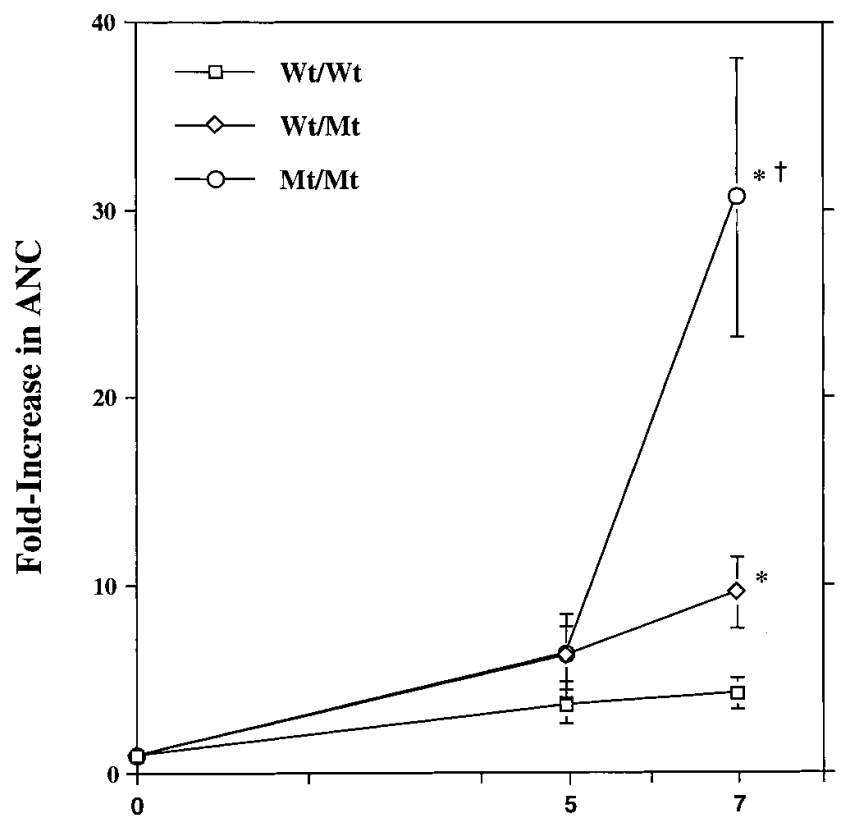

Days of G-CSF Treatment

Figure 3. In vivo peripheral blood neutrophil response to G-CSF. Five age and sex-matched wild-type $(W t / W t)$, heterozygous $(W t / M t)$, or homozygous mutant $(M t / M t)$ mice were injected subcutaneously with human G-CSF $(10 \mu \mathrm{g} / \mathrm{kg} /$ day $)$ for $7 \mathrm{~d}$. Complete blood counts and 300-count manual leukocyte differentials were performed before the first injection and $4 \mathrm{~h}$ after the injections on day 5 or 7 . The foldincrease in the absolute neutrophil counts $(A N C)$ from baseline is shown. Data represent the mean \pm SEM. $* P<.05$ compared with Wt/ Wt mice. ${ }^{\dagger} P<.05$ compared with $\mathrm{Wt} / \mathrm{Mt}$ mice. 

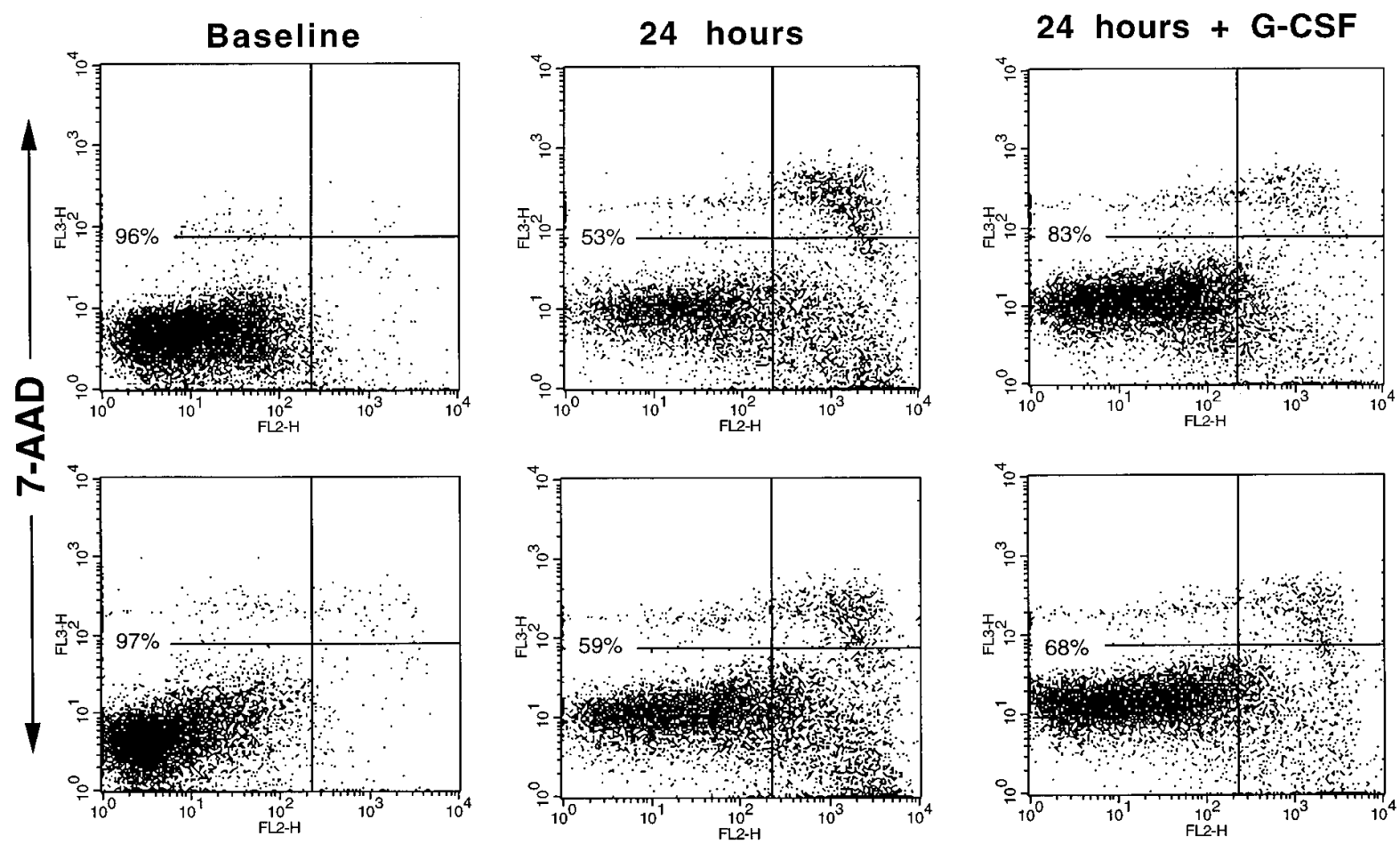

$M \mathbf{t} / \mathbf{M t}$
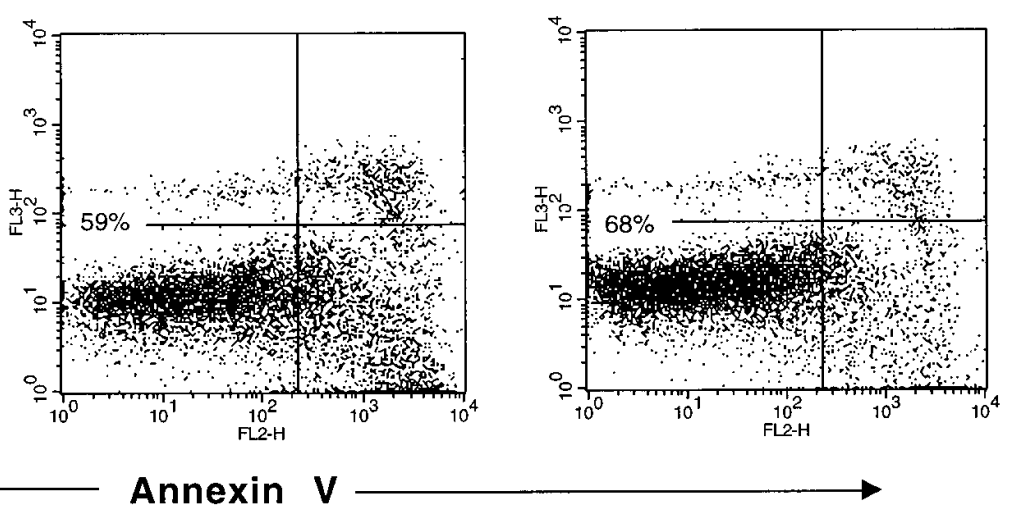

$W t / W t$

Figure 4. G-CSF-mediated suppression of neutrophil apoptosis. Neutrophils were isolated from the bone marrow and cultured in the presence or absence of $100 \mathrm{ng} / \mathrm{mL}$ of G-CSF. Cells were harvested at the initiation of culture (baseline) or after $24 \mathrm{~h}$ of culture and incubated with Annexin V and 7-AAD. Apoptotic cells stain only with Annexin V (lower right quadrant), whereas nonviable cells are positive for both 7-AAD and Annexin V (upper right quadrant). The percentage of viable nonapoptotic (7-AAD-negative/Annexin V-negative) cells is shown. Forward and side scatter characteristics were used to gate on the neutrophil population (not shown). Shown are representative results of one of four experiments.

agreement with this observation, the average number of cells per colony on day 10 of culture was $1,400,2,300$, or 2,100 for $\mathrm{Wt} / \mathrm{Wt}, \mathrm{Wt} / \mathrm{Mt}$, or $\mathrm{Mt} / \mathrm{Mt}$, respectively. Cytological examination of G-CSF-stimulated colonies on day 10 demonstrated a similar percentage of mature neutrophils: 41,44 , or $41 \%$ for $\mathrm{Wt} / \mathrm{Wt}$, Wt/Mt, or Mt/Mt, respectively. These data demonstrate that the absolute number of G-CSF-responsive progenitors in the bone marrow of mice carrying the targeted G-CSFR mutation is increased and suggest that these progenitors have an increased proliferative response to G-CSF.

No cases of AML or MDS have been detected in G-CSFR mutant mice. A prominent feature of $\mathrm{SCN}$ is the high rate of MDS or AML in those patients who have G-CSFR mutations $(2,10)$. To determine if expression of the truncated G-CSFR by itself is leukemogenic, a tumor watch was established. A total of $40 \mathrm{Wt} / \mathrm{Mt}$ and $40 \mathrm{Mt} / \mathrm{Mt}$ mice, along with $36 \mathrm{Wt} / \mathrm{Wt}$ mice as controls, have been followed for a median of 7 mo (range 4-10 mo) with periodic peripheral blood analysis. To date, no cases of AML or MDS have been observed, and in fact, no alteration of peripheral blood counts has been detected (Table I). Because there has been some concern that the chronic use of G-CSF may alter the incidence and/or latency of AML in SCN (2), a separate cohort of mice has been treated chronically with G-CSF $(250 \mu \mathrm{g} / \mathrm{kg}$, biweekly). A total of $9 \mathrm{Wt} / \mathrm{Wt}, 11 \mathrm{Wt} /$ $\mathrm{Mt}$, and $7 \mathrm{Mt} / \mathrm{Mt}$ mice have been treated for a median of 6 mo.
To date, no cases of AML or MDS have been observed in this cohort of mice.

\section{Discussion}

Mutations of the G-CSFR have been hypothesized to play a role in the pathogenesis of SCN and/or the development of AML or MDS. To directly test this hypothesis, we generated mice that carry a targeted mutation of their G-CSFR that reproduces the mutation found in a patient with SCN and AML. Mice carrying this mutant G-CSFR gene are viable, with normal growth and development. The mutant G-CSFR protein is present at the cell surface, binds G-CSF, and is expressed in a myeloid-specific fashion. Surprisingly, mice heterozygous or homozygous for this mutation have normal levels of circulating neutrophils and no evidence for a block in myeloid maturation, indicating that resting granulopoiesis is normal. In fact, in response to G-CSF treatment, these mice demonstrate a significantly greater fold increase in the level of circulating neutrophils. Despite this evidence for a hyperproliferative response to G-CSF, no cases of AML have been detected to date.

The role of G-CSFR mutations in the pathogenesis of SCN is unclear. Point mutations that cluster in a very narrow range (nucleotides 2,384-2,429) of the G-CSFR gene occur in $~ 25 \%$ of patients with SCN (10-13). Interestingly, these mutations 

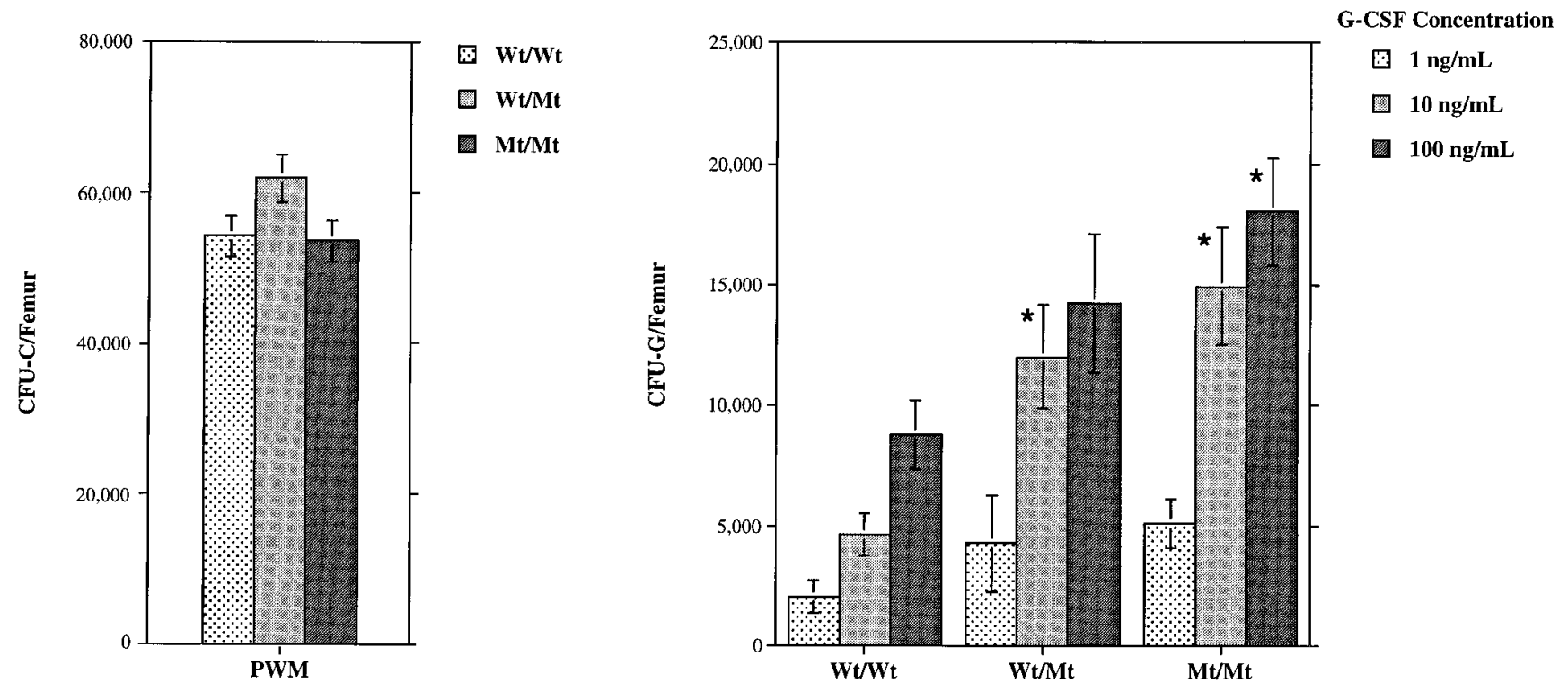

Figure 5. Hematopoietic progenitor assays. Bone marrow mononuclear cells were plated in methylcellulose-containing media supplemented with $(A)$ pokeweed mitogen-stimulated spleen-conditioned media $(P W M)$ or $(B)$ the indicated amount of G-CSF. Hematopoietic colonies containing 50 or more cells were scored on day $7 . \mathrm{Wt} / \mathrm{Wt}, \mathrm{Wt} / \mathrm{Mt}$, and $\mathrm{Mt} / \mathrm{Mt}$ refer to wild-type, heterozygous, and homozygous mutant mice, respectively. Data represent the mean \pm SEM. $* P<.05$ compared to Wt/Wt at the corresponding G-CSF concentration.

appear to be unique to SCN as they have not yet been reported in other neutropenic syndromes ( 0 of 18 tested) or in healthy subjects ( 0 of 30 tested) $(10,26,27)$. These mutations all result in the generation of a premature stop codon that leads to a truncation of the distal cytoplasmic region of the G-CSFR (10-13). In vitro studies have suggested the presence of two functional domains of the cytoplasmic region of the G-CSFR. The membrane proximal cytoplasmic region has been shown to be necessary and sufficient for the generation of proliferative signals (14-16). The distal cytoplasmic region (the area deleted in SCN-related G-CSFR mutations) has been implicated in maturation signaling (14-16). Indeed, expression of the truncated G-CSFR in a myeloid cell line blocked G-CSF-dependent granulocytic differentiation even in the presence of wild-type receptor $(12,14)$. These data have led to the hypothesis that the G-CSFR mutations may play a role in the pathogenesis of SCN. However, a recent study of two unrelated families with SCN showed that G-CSFR mutations were acquired and did not effect the degree of neutropenia or response to G-CSF (13).

In the current study, we show that mice homozygous or heterozygous for the mutated G-CSFR have normal levels of circulating neutrophils and no evidence of a block in myeloid maturation. Interestingly, Hermans et al. recently reported that mice carrying a similar mutation of the G-CSFR were mildly neutropenic (28). The reasons for the difference in the resting level of circulating neutrophils in these two mutant mouse lines are unclear but may include differences in the targeting strategy and strain of mice used. Nonetheless, in neither study was the cardinal feature of SCN, severe neutropenia with a block in myeloid maturation, observed. These data therefore provide further strong evidence that the G-CSFR mutations are not sufficient to induce an SCN phenotype.
The role of G-CSFR signals in the terminal differentiation of myeloid precursors to neutrophils is controversial. Several in vitro studies have suggested that the distal cytoplasmic region of the G-CSFR is required for the granulocytic differentiation of certain myeloid cell lines $(12,14,15)$. In contrast, mice lacking any functional G-CSFR protein still produce mature neutrophils, albeit at a reduced level $(17,29)$. The study of G-CSFR-deficient mice demonstrated that the G-CSFR was not required for the terminal differentiation of neutrophils but did not rule out a role for G-CSFR signals in normal granulocytic differentiation or function. In fact, we recently have discovered that neutrophils isolated from G-CSFR-deficient mice have significant functional defects suggesting that the G-CSFR is providing nonredundant signals essential for mature neutrophil function (our manuscript in preparation). In the present study, we show that mice expressing only the mutant G-CSFR have normal levels of circulating mature-appearing neutrophils and that G-CSF-dependent production of mature neutrophils from progenitor cells in vitro is normal. These data suggest that the distal cytoplasmic region of the G-CSFR deleted in patients with SCN is not required for the G-CSF-stimulated terminal differentiation of neutrophils. This region comprises $\sim 50 \%$ of the cytoplasmic tail (including three of four tyrosines) and has been shown to be required for the activation of SHC and the JNK/SAPK pathway (30-32). The complete biological implications of the loss of this region and its signaling pathways are yet to be determined. Studies are currently underway to examine the effect of this mutation on mature neutrophil function.

In this study, we show that mice expressing a truncated G-CSFR demonstrate a significantly greater increase in the level of circulating neutrophils in response to G-CSF than 
wild-type mice. This accentuated response could either be due to a prolonging of neutrophil survival or increased neutrophil production. Recent studies of the effects of exogenous G-CSF on normal hosts have failed to detect an effect on neutrophil survival $(33,34)$. Furthermore, we show that the survival and G-CSF-dependent suppression of apoptosis of mutant neutrophils in vitro is normal. Although indirect, these data provide evidence against a significant prolongation of neutrophil survival in vivo in mutant mice. The most dramatic increase in neutrophil counts occurred relatively late (Fig. 3, compare data on day 5 with day 7) and is consistent with the stimulation of a progenitor population $(33,35)$. Consistent with this conclusion, both the absolute number of G-CSF-responsive progenitors in the bone marrow of G-CSFR mutant mice and their proliferative response to G-CSF in vitro was increased. Interestingly, the Mt/Mt mice had a significantly greater peripheral neutrophil response to G-CSF than Wt/Mt mice, yet the absolute number of CFU-G in the bone marrow of these mice was similar. This observation suggests that other mechanisms besides an expanded pool of CFU-G may be contributing to the accentuated response to G-CSF in vivo.

The molecular mechanism(s) responsible for the increased proliferative response of the truncated G-CSFR is currently not known. Recently, mutations of the erythropoietin receptor that lead to the deletion of the carboxy-terminal tail have been described in patients with familial erythrocytosis (36-39). Progenitors expressing this truncated erythropoietin receptor are hypersensitive to erythropoietin and demonstrate a defect in hematopoietic cell phosphatase (HCP) activation $(36,37)$. Interestingly, bone marrow cells isolated from viable motheaten mice that express reduced amounts of functional HCP, demonstrate an increased proliferative response to both G-CSF and erythropoietin $(40,41)$. However, in contrast to the erythropoietin receptor, a direct interaction between $\mathrm{HCP}$ and the G-CSFR has not been demonstrated (40). Whether HCP activation is altered by the G-CSFR mutation will require further study. More recently, a report has suggested the importance of a di-leucine motif (within the deleted portion of the G-CSFR) for receptor internalization (42). In this regard, it is interesting to note the modest, but reproducible, increase in G-CSF binding by neutrophils expressing the mutant G-CSFR. Further studies will be required to determine whether impaired receptor internalization contributes to the hyperproliferative response.

Patients with SCN and a mutation of their G-CSFR appear to be at much greater risk for developing AML than patients without G-CSFR mutations $(2,10)$. In fact, no patient with SCN but without a G-CSFR mutation is known to have developed AML. It has been speculated that the uncoupling of maturation from proliferative signals by the truncated G-CSFR may contribute to leukemogenesis. As discussed above, we have evidence that the truncated receptor is associated with an increased proliferative response to G-CSF in vivo. To determine whether this hyperproliferative phenotype is associated with the development of myeloproliferative disease, we established a tumor watch. With a median follow-up of over 7 mo, no cases of AML or MDS have been identified in mice carrying this mutation. In addition, no cases of AML or MDS have been detected in mice chronically treated with G-CSF (median duration of G-CSF treatment is $6 \mathrm{mo}$ ); a clinically relevant result as there has been some concern that G-CSF treatment may alter the incidence of AML in patients with SCN. Al- though preliminary, these data suggest that the G-CSFR mutation is not sufficient to induce AML or MDS in mice. However, these data do not exclude a role for G-CSFR mutations in the development of AML or MDS in patients with SCN. Of note, only 1 out of 58 patients with de novo AML and 0 of 29 patients with chronic myelogenous leukemia in blast crisis have been found to have a similar mutation, suggesting an unique association between SCN and G-CSFR mutations (26, 27). It is possible that the combination of a G-CSFR mutation and the (currently unknown) genetic mutation responsible for SCN are required to substantially increase the risk of developing AML or MDS.

In summary, these data demonstrate that the G-CSFR mutation found in patients with $\mathrm{SCN}$ is not sufficient to induce an SCN phenotype in mice. This result provides strong evidence that these mutations are not responsible for the impaired granulopoiesis present in patients with SCN. In fact, the results of this study suggest that expression of the mutant G-CSFR on myeloid progenitors may ren

der them hyper-responsive to G-CSF. Whether this altered GCSF-responsiveness contributes to the development of AML and/or MDS in these patients will require further study.

\section{Acknowledgments}

We thank Tim Corbin and Pam Goda for their expert technical assistance in the generation of the G-CSFR mutant mice. We thank Timothy J. Ley for his critical review of this manuscript.

This work was supported by a grant from the American Cancer Society (DCL) and by a training grant from the National Institutes of Health NHLBI (T32 HL 07088-23; MLM).

\section{References}

1. Kostmann, R. 1956. Infantile genetic agranulocytosis: a new recessive lethal disease in man. Acta Paediatr. 105:1-78.

2. Welte, K., and D. Dale. 1996. Pathophysiology and treatment of severe chronic neutropenia. Ann. Hematol. 72:158-165.

3. Dale, D.C., M.A. Bonilla, M.W. Davis, A.M. Nakanishi, W.P. Hammond, J. Kurtzberg, W. Wang, A. Jakubowski, E. Winton, P. Lalezari, et al. 1993. A randomized controlled phase III trial of recombinant human granulocyte colony-stimulating factor (filgrastim) for treatment of severe chronic neutropenia. Blood. 81:2496-2502.

4. Bonilla, M.A., D. Dale, C. Zeidler, L. Last, A. Reiter, M. Ruggeiro, M. Davis, B. Koci, W. Hammond, A. Gillio, et al. 1994. Long-term safety of treatment with recombinant human granulocyte colony-stimulating factor ( $\mathrm{r}$ metHuG-CSF) in patients with severe congenital neutropenias. Br. J. Haematol. 88:723-730.

5. Mempel, K., T. Pietsch, T. Menzel, C. Zeidler, and K. Welte. 1991. Increased serum levels of granulocyte colony-stimulating factor in patients with severe congenital neutropenia. Blood. 77:1919-1922.

6. Bernhardt, T.M., E.R. Burchardt, and K. Welte. 1993. Assessment of G-CSF and GM-CSF mRNA expression in peripheral blood mononuclear cells from patients with severe congenital neutropenia and in human myeloid leukemic cell lines. Exp. Hematol. 21:163-168.

7. Guba, S.C., C.A. Sartor, R. Hutchinson, L.A. Boxer, and S.G. Emerson. 1994. Granulocyte colony-stimulating factor (G-CSF) production and G-CSF receptor structure in patients with congenital neutropenia. Blood. 83:14861492.

8. Sandoval, C., E. Parganas, W. Wang, J.N. Ihle, and P. Adams-Graves. 1995. Lack of alterations in the cytoplasmic domains of the granulocyte colonystimulating factor receptors in eight cases of severe congenital neutropenia [letter]. Blood. 85:852-853.

9. Kyas, U., T. Pietsch, and K. Welte. 1992. Expression of receptors for granulocyte colony-stimulating factor on neutrophils from patients with severe congenital neutropenia and cyclic neutropenia. Blood. 79:1144-1147.

10. Welte, K., and I.P. Touw. 1997. G-CSF receptor mutations in patients with severe chronic neutropenia: a step in leukemogenesis? Blood. 90:1921A.

11. Dong, F., L.H. Hoefsloot, A.M. Schelen, C.A. Broeders, Y. Meijer, A.J. Veerman, I.P. Touw, and B. Lowenberg. 1994. Identification of a nonsense mutation in the granulocyte colony-stimulating factor receptor in severe congenital neutropenia. Proc. Natl. Acad. Sci. USA. 91:4480-4484. 
12. Dong, F., R.K. Brynes, N. Tidow, K. Welte, B. Lowenberg, and I.P. Touw. 1995. Mutations in the gene for the granulocyte colony-stimulating-factor receptor in patients with acute myeloid leukemia preceded by severe congenital neutropenia [see comments]. N. Engl. J. Med. 333:487-493.

13. Tidow, N., C. Pilz, B. Teichmann, A. Muller-Brechlin, M. Germeshausen, B. Kasper, P. Rauprich, K.W. Sykora, and K. Welte. 1997. Clinical relevance of point mutations in the cytoplasmic domain of the granulocyte colonystimulating factor receptor gene in patients with severe congenital neutropenia. Blood. 89:2369-2375.

14. Dong, F., C. van Buitenen, K. Pouwels, L.H. Hoefsloot, B. Lowenberg, and I.P. Touw. 1993. Distinct cytoplasmic regions of the human granulocyte colony-stimulating factor receptor involved in induction of proliferation and maturation. Mol. Cell. Biol. 13:7774-7781.

15. Fukunaga, R., E. Ishizaka-Ikeda, and S. Nagata. 1993. Growth and differentiation signals mediated by different regions in the cytoplasmic domain of granulocyte colony-stimulating factor receptor. Cell. 74:1079-1087.

16. Ziegler, S.F., T.A. Bird, K.K. Morella, B. Mosley, D.P. Gearing, and H. Baumann. 1993. Distinct regions of the human granulocyte-colony-stimulating factor receptor cytoplasmic domain are required for proliferation and gene induction. Mol. Cell. Biol. 13:2384-2390.

17. Liu, F., H.Y. Wu, R. Wesselschmidt, T. Kornaga, and D.C. Link. 1996. Impaired production and increased apoptosis of neutrophils in granulocyte colony-stimulating factor receptor-deficient mice. Immunity. 5:491-501.

18. Barettino, D., M. Feigenbutz, R. Valcarcel, and H.G. Stunnenberg. 1994. Improved method for PCR-mediated site-directed mutagenesis. Nucleic Acids Res. 22:541-542.

19. Hug, B.A., R.L. Wesselschmidt, S. Fiering, M.A. Bender, E. Epner, M. Groudine, and T.J. Ley. 1996. Analysis of mice containing a targeted deletion of $\beta$-globin locus control region 5' hypersensitive site 3. Mol. Cell. Biol. 16: 2906-2912.

20. Chomczynski, P., and N. Sacchi. 1987. Single-step method of RNA isolation by acid guanidinium thiocyanate-phenol-chloroform extraction. Anal. Biochem. 162:156-159.

21. Lowell, C.A., L. Fumagalli, and G. Berton. 1996. Deficiency of Src family kinases P59/61hck and p58c-fgr results in defective adhesion-dependent neutrophil functions. J. Cell Biol. 133:895-910.

22. Roberts, A., S. Foote, W. Alexander, C. Scott, L. Robb, and D. Metcalf. 1997. Genetic influences determining progenitor cell mobilization and leukocytosis induced by granulocyte colony-stimulating factor. Blood. 89:2736-2744.

23. Homburg, C.H.E., M. de Haas, A.E. von dem Borne, A.J. Verhoeven, C.P. Reutelingsperger, and D. Roos. 1995. Human neutrophils lose their surface FcgRIII and acquire Annexin $\mathrm{V}$ binding sites during apoptosis in vitro. Blood. 85:532-540.

24. Koopman, G., C.P.M. Reutelingsperger, G.A.M. Kuijten, R.M.J. Keehnen, S.T. Pals, and M.H.J. van Oers. 1994. Annexin V for flow cytometric detection of phosphatidylserine expression on B cells undergoing apoptosis. Blood. 84:1415-1420.

25. Martin, S.J., C.P. Reutelingsperger, A.J. McGahon, J.A. Rader, R.C. van Schie, D.M. LaFace, and D.R. Green. 1995. Early redistribution of plasma membrane phosphatidylserine is a general feature of apoptosis regardless of the initiating stimulus:inhibition by overexpression of Bcl-2 and Abl. J. Exp. Med. $182: 1545-1556$

26. Bernard, T., R.E. Gale, and D.C. Linch. 1996. Analysis of granulocyte colony-stimulating factor receptor isoforms, polymorphisms and mutations in normal haemopoietic cells and acute myeloid leukaemia blasts. Br. J. Haematol.
93:527-533

27. Carapeti, M., A. Soede-Bobok, A. Hochhaus, H. Sill, I.P. Touw, J.M Goldman, and N.C. Cross. 1997. Rarity of dominant-negative mutations of the G-CSF receptor in patients with blast crisis of chronic myeloid leukemia or de novo acute leukemia. Leukemia. 11:1005-1008.

28. Hermans, M.H.A., C. Antonissen, A. Karis, A.C. Ward, C.D. Jongh, and I.P. Touw. 1997. Mice with a targeted G-CSF receptor mutation derived from severe congenital neutropenia have reduced absolute neutrophil counts but are not severely neutropenic. Blood. 90:1822a.

29. Liu, F., J. Poursine-Laurent, H. Wu, and D. Link. 1997. IL-6 and the G-CSF receptor are major independent regulators of granulopoiesis in vivo but are not required for lineage commitment or terminal differentiation. Blood. 90: 2583-2590.

30. de Koning, J.P., A.M. Schelen, F. Dong, C. van Buitenen, B.M. Burgering, J.L. Bos, B. Lowenberg, and I.P. Touw. 1996. Specific involvement of tyrosine 764 of human granulocyte colony-stimulating factor receptor in signa transduction mediated by $\mathrm{p} 145 / \mathrm{Shc} / \mathrm{GRB} 2$ or p90/GRB2 complexes. Blood. 87: $132-140$.

31. Rausch, O., and C.J. Marshall. 1997. Tyrosine 763 of the murine granulocyte colony-stimulating factor receptor mediates Ras-dependent activation of the JNK/SAPK mitogen-activated protein kinase pathway. Mol. Cell. Biol. 17: 1170-1179.

32. Avalos, B.R. 1996. Molecular analysis of the granulocyte colony-stimulating factor receptor. Blood. 88:761-777.

33. Lord, B.I., M.H. Bronchud, S. Owens, J. Chang, A. Howell, L. Souza, and T.M. Dexter. 1989. The kinetics of human granulopoiesis following treatment with granulocyte colony-stimulating factor in vivo. Proc. Natl. Acad. Sci. USA. 86:9499-9503.

34. Price, T.H., G.S. Chatta, and D.C. Dale. 1996. Effect of recombinant granulocyte colony-stimulating factor on neutrophil kinetics in normal young and elderly humans. Blood. 88:335-340.

35. Lord, B.I., G. Molineux, Z. Pojda, L.M. Souza, J.-J. Mermod, and T.M Dexter. 1991. Myeloid cell kinetics in mice treated with recombinant interleukin-3, granulocyte colony-stimulating factor (CSF), or granulocyte-macrophage CSF in vivo. Blood. 77:2154-2159.

36. de la Chapelle, A., A.L. Traskelin, and E. Juvonen. 1993. Truncated erythropoietin receptor causes dominantly inherited benign human erythrocytosis. Proc. Natl. Acad. Sci. USA. 90:4495-4499.

37. Klingmuller, U., U. Lorenz, L.C. Cantley, B.G. Neel, and H.F. Lodish. 1995. Specific recruitment of SH-PTP1 to the erythropoietin receptor causes inactivation of JAK2 and termination of proliferative signals. Cell. 80:729-738

38. Kralovics, R., K. Indrak, T. Stopka, B.W. Berman, J.F. Prchal, and J.T. Prchal. 1997. Two new EPO receptor mutations: truncated EPO receptors are most frequently associated with primary familial and congenital polycythemias. Blood. 90:2057-2061.

39. Gregg, X.T., and J.T. Prchal. 1997. Erythropoietin receptor mutations and human disease. Semin. Hematol. 34:70-76.

40. Tapley, P., N.K. Shevde, P.A. Schweitzer, M. Gallina, S.W. Christianson, I.L. Lin, R.B. Stein, L.D.Shultz, J. Rosen, and P. Lamb. 1997. Increased G-CSF responsiveness of bone marrow cells from hematopoietic cell phosphatase deficient viable motheaten mice. Exp. Hematol. 25:122-131.

41. Van Zant, G., and L. Shultz. 1989. Hematologic abnormalities of the immunodeficient mouse mutant, viable motheaten (mev). Exp. Hematol. 17:81-87.

42. Hunter, M., and B. Avalos. 1997. A dileucine motif in the G-CSFR may mediate the dominant negative phenotype in SCN/AML. Blood. 90:1923a. 